\title{
A primeira guerra do Paraguai: a expedição naval do Império do Brasil a Assunção (1854-1885)
}

Silvânia de Queiróz ${ }^{*}$

O historiador Fabiano Barcellos Teixeira realizou um belíssimo trabalho em sua obra A primeira guerra do Paraguai: a expedição naval do Império do Brasil a Assunção (1854-1855). Com maestria, Teixeira explora um tema pouquíssimo estudado pela historiografia platina, a imponente expedição naval feita pelo Império do Brasil ao Paraguai, sob o comando do chefe de esquadra Pedro Ferreira de Oliveira.

Publicado em 2012, pela editora Méritos, o livro tem 183 páginas organizadas em oito capítulos, contemplando desde a formação do Império do Brasil, da Argentina, do Uruguai e do Paraguai até a construção da política e da diplomacia na América Platina, com destaque minucioso para causas, itinerários, principais acontecimentos e consequências da expedição que o autor sagazmente intitula de a primeira guerra do Paraguai.

A obra é resultado da dissertação do curso de mestrado em História do autor, realizado na Universidade de Passo Fundo (UPF), que foi defendida em 2010 e orientada pelo célebre historiador Mário Maestri, com banca dos professores Alejandro Miguel Schneider (Universidade de Buenos Aires) e Ana Luiza Setti Reckziegel (UPF).

Fabiano Barcellos Teixeira inicia sua obra com uma análise sobre o contexto histórico e político da formação da América Platina, período marcado por conflitos que culminaram na Guerra da Tríplice Aliança contra o Paraguai (1864-1870), embate que traz consequências até os dias atuais. Historicamente, a Coroa portuguesa e o Império do Brasil sempre tiveram interesses em conquistar a hegemonia da região platina, em boa parte colonizada pelos espanhóis. Um momento explícito da política expansionista luso-brasileira foi a expedição fortemente armada enviada ao Paraguai, em 1854-1855, definida por alguns autores simplesmente como o maior fiasco militar do Brasil Imperial.

\footnotetext{
Doutoranda em História pela Universidade de Passo Fundo, RS.
}

Recebido em 06/04/2015 - Aprovado em 27/04/2015
http://dx.doi.org/10.5335/hdtv.15n.2.5652 


\section{Antecedentes}

Nos anos que antecederam a Guerra da Tríplice Aliança, ocorreu uma constante disputa pela hegemonia da região platina, sobretudo entre o Império do Brasil e a Argentina. Nesse processo, também houve uma série de negociações entre o Império e o Paraguai, com o intuito de estabelecer a livre navegação do rio Paraguai e os limites territoriais no atual Mato Grosso do Sul, uma área reivindicada por ambos os países.

No século XIX, as relações entre o Império e o Paraguai foram marcadas por tensão e desconfiança. Durante o governo Francia (1811-1840), as relações eram não oficiais, pois o Império temia uma represália da Argentina, que tratava o Paraguai como uma província desgarrada. Com a morte do presidente Francia, o governo paraguaio passou para Carlos Antonio López (1844-1862). A princípio, as relações entre Paraguai e Império tornaram-se mais estáveis, pois alguns acordos diplomáticos foram chancelados na tentativa de enfraquecer a influência da Argentina, comandada pelo caudilho bonaerense Juan Manuel de Rosas.

Em 1850, disputando a palmo o domínio de parte do atual Mato Grosso do Sul, a guerra entre Paraguai e Império do Brasil não se efetivou devido à iminência do confronto com a Argentina de Rosas, para o qual eram aliados. Desinteressava à política expansionista imperial a recriação do Vice-Reinado do Prata e o provável fechamento da navegação via estuário do Prata, e, por sua vez, o governo do Paraguai desejava ratificar sua independência entre as nações e usufruir o direito de acesso ao mar. Essas preocupações levaram os dois países a assinarem, em 25 de dezembro de 1850, um tratado de defesa mútua em caso de ataque da Confederação Argentina e a livre navegação de navios imperiais no rio Paraguai. Porém, com a derrota de Rosas na batalha de monte Caseros, em 1852, Império e Paraguai recrudescem as divergências sobre territórios limítrofes e sobre a navegação fluvial via rio Paraguai, rota vital para o acesso à província do Mato Grosso.

Em 7 de julho de 1852, o capitão-tenente da marinha Felipe José Pereira Leal foi nomeado plenipotenciário imperial no Paraguai, tendo por objetivo ajustar questões de navegação e limites territoriais. Contudo, não houve entendimento com o presidente Carlos Antonio López, e, em agosto de 1853, o diplomata imperial foi expulso do Paraguai. As relações diplomáticas entre os dois países estavam rompidas. Possivelmente por estar envolvido em conflitos civis no Uruguai, o Império do Brasil adiou, para o final de 1854, a represália ao Paraguai. Seria uma resposta para demonstrar quem realmente mandava no continente.

\section{A missão Pedro Ferreira de 0liveira}

Em 29 de novembro de 1854, o imperador Pedro II e o ministro dos Negócios Estrangeiros do Império, Antonio Paulino Limpo de Abreu, assinaram dois documentos endereçados ao governo paraguaio, sobre as questões pendentes entre o Império e o Paraguai, documentos que só foram entregues em 20 de fevereiro de 1855, quando a esquadra imperial chegou ao Paraguai.

Conforme Fabiano Barcellos Teixeira, a expedição foi liderada pelo político e chefe da 
marinha imperial Pedro Ferreira de Oliveira, que contava com a confiança do imperador. Em 10 de dezembro de 1854, a expedição partiu do Rio de Janeiro, contando com mais de trinta navios de guerra, armados com 150 canhões e cerca de 3 mil soldados. Era a diplomacia da canhoneira chegando ao Paraguai.

A expedição devia contar com o fator surpresa, mas Teixeira descreve a existência de uma rede de informações e informantes - políticos, militares, comerciantes - desde Rio de Janeiro, São Borja e Encarnación, que levavam notícias sobre as ações imperiais até Assunção. Em 2 de dezembro de 1854, a informação sobre o possível ataque imperial foi revelada à população. O Paraguai aumentou sua vigília das tropas, evacuou a capital e buscou se precaver com o uso de normas do direito internacional. Nesse mesmo período, entrou em atrito com o navio estadunidense Water Witch (Bruxa das Águas), devido à navegação do rio Paraguai.

O então ministro das relações exteriores do Paraguai, Francisco Solano López, com sua comitiva, atracou no Porto de Rio de Janeiro, em 23 de dezembro de 1854, quando retornava de missão à Europa. Ele conseguiu uma cópia das instruções "secretas" da missão de Pedro Ferreira de Oliveira com seu representante no Rio de Janeiro, o redator do Jornal do Commercio Manuel Moreira de Castro, figura que tinha importantes contatos com políticos imperiais.

\section{As instruções e o poder de fogo}

Segundo as instruções da diplomacia imperial, Pedro Ferreira de Oliveira deveria convencer o Paraguai a aceitar a proposta sobre os limites territoriais e a livre navegação no rio Paraguai, em até oito dias, senão seriam deslocados de trezentos a quatrocentos soldados para o atual Mato Grosso do Sul. Ele devia tentar primeiro a via pacífica, depois, caso necessário, a força.

Segundo Teixeira, as condições de navegação nos rios da bacia do Prata eram difíceis para os pesados navios imperiais. Em vários trechos os navios do Império acabaram encalhando, o que acarretava em demora na navegação. Em 20 de fevereiro de 1855, após 72 dias, a esquadra finalmente chegou à fronteira com o Paraguai, sendo advertida pelo capitão paraguaio Pedro Ignazio Meza que seguisse a Assunção em uma só embarcação. Pedro Ferreira de Oliveira seguiu na Fragata Amazonas, que, em parte do trajeto, também encalhou e foi rebocada por navios paraguaios.

O autor fez descrição detalhada sobre a formação da esquadra, destacando origem, fabricação e poder de fogo, assim como apresentou discussão sobre artigos de jornais do Império e da Argentina, que analisaram a expedição. No Império não havia consenso sobre a necessidade da expedição, e na Argentina buscava-se justificar a permissão da passagem da esquadra imperial em água de sua jurisdição, por ser o Império uma nação amiga e em missão pacífica.

Em 20 de abril de 1855, o Jornal do Commercio afirmava que os marinheiros estavam entusiasmados, tanto a tropa de linha como as guarnições da esquadra estariam se exercitando regularmente no manejo de artilharia e de outras armas. A reportagem mostrava expectativa positiva da esquadra e certa preferência de alguns membros pela guerra, 
pois assim encontrariam uma oportunidade de ascender na Marinha.

\section{As conferências em Assunção}

De acordo com informações do governo paraguaio, o Império do Brasil enviou a expedição naval de Pedro Ferreira de Oliveira sem nenhum comunicado oficial, sendo assim, não teria razões para recebê-lo. Contudo, buscando evitar a guerra, Solano López ficou encarregado de negociar com o plenipotenciário imperial. A esquadra imperial deveria sair imediatamente das águas paraguaias e seu comandante deveria prosseguir em apenas um navio até Assunção, caso contrário, o governo paraguaio se defenderia, iniciando a batalha, advertiu o negociador Solano López.

Pedro Ferreira de Oliveira optou pela diplomacia. Em 24 de março de 1855, chegou a Assunção a bordo da corveta Ipiranga, onde foi realizado desagravo formal à bandeira imperial, com 21 tiros cerimoniais, em atenção à expulsão do ministro imperial Felipe José Pereira Leal, ocorrida em agosto de 1853, assim como a corveta Ipiranga também saudou a bandeira paraguaia. O Paraguai justificava, no caso Leal, que não estava agindo contra o Império, buscava retratar-se. Na verdade, o caso Leal foi só uma escusa para justificar a tentativa de intervenção no Paraguai.

Pedro Ferreira de Oliveira e Francisco Solano López iniciaram as negociações em 3 de abril de 1855. Os dois acordaram que primeiramente iriam tratar sobre a questão de limites. Ocorreram conferências em 3, 9, 11 e 14 de abril, nas quais, entre os pontos principais, tratava-se da discussão sobre o direito do uti possidetis. O ponto de discórdia estava na posse da região entre o rio Apa, mais ao sul, e o rio Branco, ambos tributários do Paraguai, que defendia uma revisão sobre as áreas ocupadas, para saber quem realmente tinha direito a elas; já Pedro Ferreira de Oliveira defendia a ideia ligada ao tratado de 1777, de que toda aquela área era portuguesa e portanto imperial. Nenhum dos lados pretendia abrir mão do território, o Império queria a livre navegação pelo rio Paraguai, mas o Paraguai só aceitava negociar mediante definição do tratado sobre as fronteiras.

Conforme Fabiano Barcellos Teixeira, as conferências assinalaram a vitória diplomática do Paraguai contra a estratégia bélica inadequada do Império. Pedro Ferreira de Oliveira foi obrigado a aceitar a tentativa pacífica de acordo, pois seria um suicídio querer atacar o Paraguai. Esse acontecimento assinalava que a guerra estava por vir.

\section{0 sentido histórico}

Em 27 de abril de 1855, em Assunção, Império do Brasil e Paraguai, por meio de seus representantes Pedro Ferreira de Oliveira e Francisco Solano López, assinaram um tratado de amizade, comércio e navegação, com 21 artigos e uma convenção adicional sobre limites, de cinco artigos. Entre as principais medidas estava o reconhecimento do pleno direito do governo paraguaio sobre o rio Paraguai na parte em que atravessa seu território, e a questão de limites seria postergada por mais um ano. 
No retorno ao Rio de Janeiro, o Império brasileiro não ratificou o tratado e insistiu no direito à livre navegação, baseado na aliança contra Rosas de 1850. O tratado foi totalmente rechaçado. Pedro Ferreira de Oliveira foi, por parte da historiografia oficial patriótica, considerado incapaz, despreparado, sendo seus feitos considerados insignificantes e propositalmente esquecidos.

Segundo Teixeira, Pedro Ferreira de Oliveira teve prudência, pois a esquadra enfrentava dificuldades e seria um alvo fácil para o exército paraguaio. O Império foi obtuso e subestimou a complexidade da operação e a capacidade de defesa do Paraguai. Nos anos que se seguiram, novos tratados foram firmados entre o Império e o Paraguai, mas nenhum foi duradouro.

De modo lúcido e elegante, Fabiano Barcellos Teixeira conduz o leitor pelos caminhos e descaminhos da história platina, trazendo luz a esse importante acontecimento. Sua obra A primeira guerra do Paraguai é referência essencial para quem busca compreender o contexto e as razões da Guerra da Tríplice Aliança contra o Paraguai. A guerra do Paraguai teve um ensaio geral, ou seja, a sua primeira guerra.

\section{Referência}

TEIXEIRA, Fabiano Barcellos. A primeira guerra do Paraguai: a expedição naval do Império do Brasil a Assunção (1854-1855). Passo Fundo: Méritos, 2012. 183p. 